\title{
Development, validation, and potential enhancements to the second-generation operational aerosol product at the National Environmental Satellite, Data, and Information Service of the National Oceanic and Atmospheric Administration
}

\author{
Larry L. Stowe and Alexander M. Ignatov ${ }^{1}$ \\ Office of Research and Applications, Satellite Research Laboratory, NOAANESDIS, Washington, D. C.
}

\author{
Ramdas R. Singh \\ SM System and Research Corporation, Inc., Bowie, Maryland
}

\begin{abstract}
A revised (phase 2) single-channel algorithm for aerosol optical thickness, $\tau_{\mathrm{SAT}}^{\mathrm{A}}$, retrieval over oceans from radiances in channel $1(0.63 \mu \mathrm{m})$ of the advanced very high resolution radiometer (AVHRR) has been implemented at the National Oceanic and Atmospheric Administration's National Environmental Satellite Data and Information Service for the NOAA 14 satellite launched December 30, 1994. It is based on careful validation of its operational predecessor (phase 1 algorithm), implemented for NOAA 11 in 1989. Both algorithms scale the upward satellite radiances in cloud-free conditions to aerosol optical thickness using an updated radiative transfer model of the ocean and atmosphere. Application of the phase 2 algorithm to three matchup Sun-photometer and satellite data sets, one with NOAA 9 in 1988 and two with NOAA 11 in 1989 and 1991, respectively, show systematic error is less than $10 \%$, with a random error of $\sigma_{\tau} \approx 0.04$. First results of $\tau_{\mathrm{SAT}}^{\mathrm{A}}$ retrievals from NOAA 14 using the phase 2 algorithm, and from checking its internal consistency, are presented. The potential two-channel (phase 3) algorithm for the retrieval of an aerosol size parameter, such as the Junge size distribution exponent, by adding either channel $2(0.83 \mu \mathrm{m})$ from the current AVHRR instrument, or a $1.6-\mu \mathrm{m}$ channel to be available on the Tropical Rainfall Measurement Mission and the NOAA-KLM satellites by 1997 is under investigation. The possibility of using this additional information in the retrieval of a more accurate estimate of aerosol optical thickness is being explored.
\end{abstract}

\section{Introduction}

The upward radiance over dark surfaces, like the open ocean in the red and near-infrared spectrum, mainly varies with concentration and type of atmospheric aerosol particles, so that information about these particles can be derived from satellite data. Aerosols backscatter solar radiation in proportion to the aerosol optical thickness $\tau^{\mathrm{A}}$ and the aerosol single scattering phase function $P^{\mathrm{A}}(\chi), \chi$ being scattering angle. The marine aerosol is almost purely scattering (albedo of single scattering $\omega \rightarrow 1$ ) when not mixed with continental sources (dust, smoke, soot) [Gordon and Morel, 1983; World Climate Program, 1983, 1986; D'Almeida et al., 1991]. The relationship between the satellite-detected radiance and $\tau^{\wedge}$ is therefore illuminationobservation geometry specific. To retrieve $\tau^{\mathrm{A}}, P^{\mathrm{A}}(\chi)$ must be known.

It was shown in some studies that the variability of $P^{A}(\chi)$ in backscatter is much less than that of $\tau^{\wedge}$. Griggs [1975] has experimentally shown that upward radiance was essentially proportional to $\tau^{\wedge}$, independent of aerosol type. Koepke and

${ }^{1}$ On leave from Marine Hydrophysics Institute, Sevastopol, Crimea, Ukrainc.

Copyright 1997 by the American Geophysical Union.

Paper number 96JD(12132.

0148-(0227/97/96JD-(12132\$09.00)
Quenzel [1979] carried out theoretical calculations for a wide range of aerosol models, representative of their natural variability, and have shown that variability of $P^{\prime}(x)$ in backscatter is well within $\approx \pm 25 \%$ (and can be lowered down to $\pm 4 \%$ if optimal scattering geometry is used), whereas $\tau^{\wedge}$ varies more than an order of magnitude. The feasibility of $\tau^{\wedge}$ retrieval from a single satellite reflectance channel using a "universal" aerosol model has been recently confirmed by Kaufman [1993], who has shown experimentally that the relationship between $\tau^{\wedge}$ and atmospheric path radiance is close to universal. Such a onechannel procedure may be viewed as a normalization of the satellite radiances to a common observation-illumination geometry and their scaling to a range of aerosol optical depths, measured by customary Sun photometry. The advantage of this procedure is that it makes satellite measurements taken in different geographical regions and in different seasons uniform, allowing their direct comparison, and scales them to a well understandable physical quantity such as the aerosol optical depth.

This has been the rationale for the development of an acrosol remote sensing capability at the National Environmental Satellite, Data, and Information Service of the National Oceanic and Atmospheric Administration (NOAA/NESDIS), which commenced in 1977 [Griggs, 1983]. The algorithm has been specifically developed for use with channcl $1(0.63 \mu \mathrm{m})$ of the advanced very high resolution radiometer (AVHRR) on- 


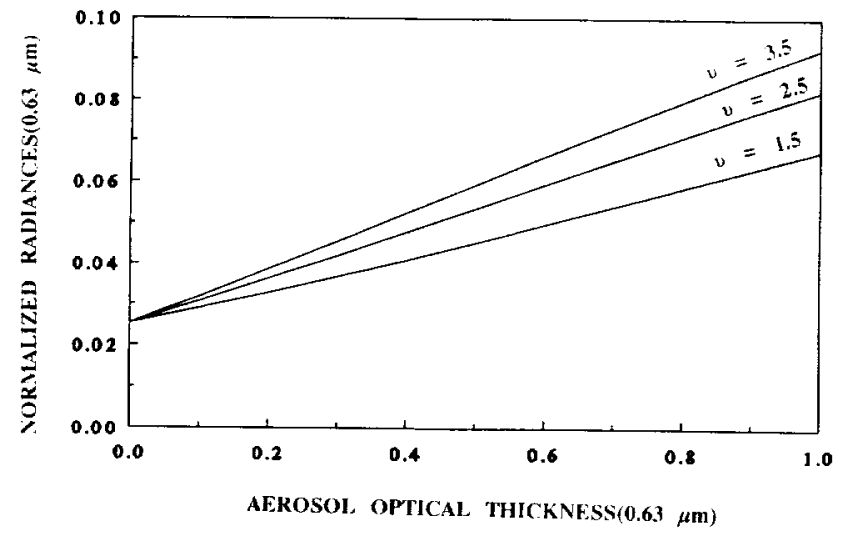

Figure 1. Dependence of reflected radiation at $0.63 \mu \mathrm{m}$ on aerosol optical thickness and $\nu$ (Junge particle size parameter) as computed from the Dave' code for the ocean/atmosphere model used in the phase 1 retrieval algorithm. Solar zenith angle is $60^{\circ}$, satellite zenith angle is $24^{\circ}$, and relative azimuth angle is $180^{\circ}$.

board NOAA polar orbiters, which provides global daily coverage on an operationally consistent long-term basis. Figure 1 illustrates the principle of the retrieval of $\tau_{\mathrm{SAT}}^{\wedge}$ from the AVHRR backscattered radiance. It shows that if the actual size of aerosol particles deviates from that used in the retrieval model ( $\nu=3.5$, see section 2 for details), than the $\tau_{\mathrm{SAT}}^{\mathrm{A}}$ retrievals would be in error. However, a ground truth experiment conducted in 1980-1981 with collocated Voltz-type Sunphotometer data sets from 10 island and coastal locations and one ship has shown that $\tau_{\hat{S A T}}^{\wedge}$ retrievals with $\nu=3.5$ have little systematic (bias) error, with a random error of $\sigma_{\tau} \approx 0.05$.

After the phase 1 algorithm was implemented into NOAA operations, another ground truth campaign was conducted, with emphasis on collocating with higher-quality Sunphotometer data from research ships [Reddy et al., 1990; Kovotyev et al., 1993]. The results of this campaign have shown a sizeable systematic underestimation by the satellite retrievals [Ignatov et al., 1995a, b]. After taking into consideration the poor quality of the 1980-1981 Sun-photometer data, it was concluded that the retrieval model used in the phase 1 algorithm was incorrect and must be revised. The phase 1 algorithm and results of its validation are described in section 2 . In its revision, extensive analysis of literature and matchup data has been performed (section 3). An improved secondgeneration (phase 2) algorithm has been formulated, validated (bias less than $10 \%$; residual random error $\sigma_{\tau} \approx 0.04$ ), and applied to data of NOAA 14, launched December 30, 1994 (section 4). Both phase 1 and 2 algorithms use only one channel, so only one unknown can be retrieved. Even though the phase 2 algorithm corresponds to an "average" aerosol better than phase 1 , it may still be prone to errors in retrieved $\tau_{\mathrm{SAT}}^{\mathrm{A}}$ because of nonuniversality of the aerosol model (resulting from seasonal and regional variability in the aerosol physical and chemical properties). Measurements in AVHRR channel $2(0.83 \mu \mathrm{m})$, or, with the launch of NOAA-K in 1996 and the Tropical Rainfall Measurement Mission (TRMM) in 1997, a third reflectance channel at $1.6 \mu \mathrm{m}$, may be potentially used to retrieve particle size information, which may be further used to reduce errors in $\tau_{\text {SAT }}^{A}$ (section 5). The value of the current product is discussed in section 6 , and concluding remarks are given in section 7.

\section{Phase 1 Algorithm (July 1987 to September 1994)}

\subsection{Algorithm Description}

The phase 1 algorithm for aerosol optical thickness $\tau_{\text {SAT }}^{A}$ retrieval has been implemented into an already existing sea surface temperature system, which incorporates procedures useful for aerosol analysis such as cloud clearing and global field analysis [McClain et al., 1985]. To avoid the influence of specular reflection from the ocean, the solar side of the orbit and measurements whose viewing angle is less than $40^{\circ}$ away from the specular ray have been excluded from the analysis. Experimental weekly production of global 8 -day $\left(1^{\circ}\right)^{2}$ composites of $\tau_{\text {SAT } 1}^{\wedge}$ from $2 \times 2$ arrays of $4-\mathrm{km}$ global area coverage pixels only over oceans commenced in July 1987 [McClain, 1989; Rao et al., 1989; Stowe, 1991]. In July 1989 these global analyses began being archived onto magnetic tape at NOAA's National Climate Data Center, Asheville, North Carolina. In January 1990 they became an operational product at NOAA/ NESDIS.

The principle of the algorithm is shown in Figure 1. At the particular geometry, the $\nu=3.5$ curve is used to retrieve $\tau_{S \mathrm{AT} 1}^{\wedge}$ from cloud-free satellite radiances $R$ at $0.63 \mu \mathrm{m}$, reduced to dimensionless reflectance by normalization to solar flux, $F_{S}$, as $L=\pi\left(R / F_{s}\right)$, and corrected for the Sun-Earth distance. $\tau_{S A T}^{A}$ is then scaled to $\lambda=0.50 \mu \mathrm{m}$, consistent with the retrieval model (multiplying by ratio of scattering coefficients (optical thicknesses) between 0.50 and $0.63 \mu \mathrm{m}, 1.348$ ). In operation the relationship between $\tau_{S \wedge T}^{\wedge}$ and $L$ is described by a four-dimensional look-up table (LUT), precalculated for different $\tau^{\wedge}$ and view-Sun-azimuth angles using Dave's [1973] scalar radiative transfer model, assuming Elterman's vertical profile of aerosol concentration $A(h)$; midlatitude ozone and water vapor profiles with integrated contents of $0.316 \mathrm{~atm} \mathrm{~cm}$ and $2.91 \mathrm{gm} \mathrm{cm}^{2}$, respectively. Other parameters to be specified as input to the LUT are Lambertian oceanic reflectance $\rho^{\text {s; }}$ the volume scattering and absorption coefficients, and the aerosol phase function, $P^{A}(\chi)$, derived from Mie calculations with a prescribed acrosol microphysical model. The oceanic albedo is set to $\rho \mathrm{s}=1.5 \%$. The aerosol model uses a modified Junge size distribution: $d N / d r=0\left(r<r_{\text {min }}\right.$ and $\left.r>r_{\text {max }}\right)$; $d N / d r=A\left(r_{\min } \leq r \leq r_{m}\right) ; d N / d r=A\left(r / r_{m}\right)(v+1)\left(r_{m} \leq\right.$ $\left.r \leq r_{\text {max }}\right)$, where $r_{\text {min }}, r_{m}, r_{\text {max }}$ are particle radii equal to 0.03 , 0.1 , and $10 \mu \mathrm{m}$, respectively; size parameter $\nu=3.5$ (equivalent Angstrom exponent $\alpha=1.5$ ); a complex index of refraction $n=1.5-0.0 i$ (albedo of single scattering, $\omega$, equals 1 ); and $A=22510 \mathrm{~cm}^{3} \mu^{-1}$ is a normalization constant dependent on an assumed number of particles per unit volume [Dave, 1973]. This model was adopted from Griggs [1983]. The specified modeled LUT establishes a unique relationship between the upward radiance and $\tau_{\text {SATI }}^{\text {A }}$ (e.g., Figure 1 ), which is further used to derive $\tau_{\text {SATI }}^{\text {a }}$ globally.

\subsection{Global Application of Phase 1 Algorithm to NOAA 11 Data}

The phase 1 algorithm has been applied to data of NOAA 11, launched in September 1988. Satellite counts have been converted to radiances using prelaunch coefficients, with an empirical adjustment described by Ignatov et al. [1995a]. This product has provided the most complete description to date of the spatial and temporal variability of tropospheric and, with the eruption of Mount Pinatubo, stratospheric aerosols over oceans. Plate 1 shows the variation with time (weekly) from 


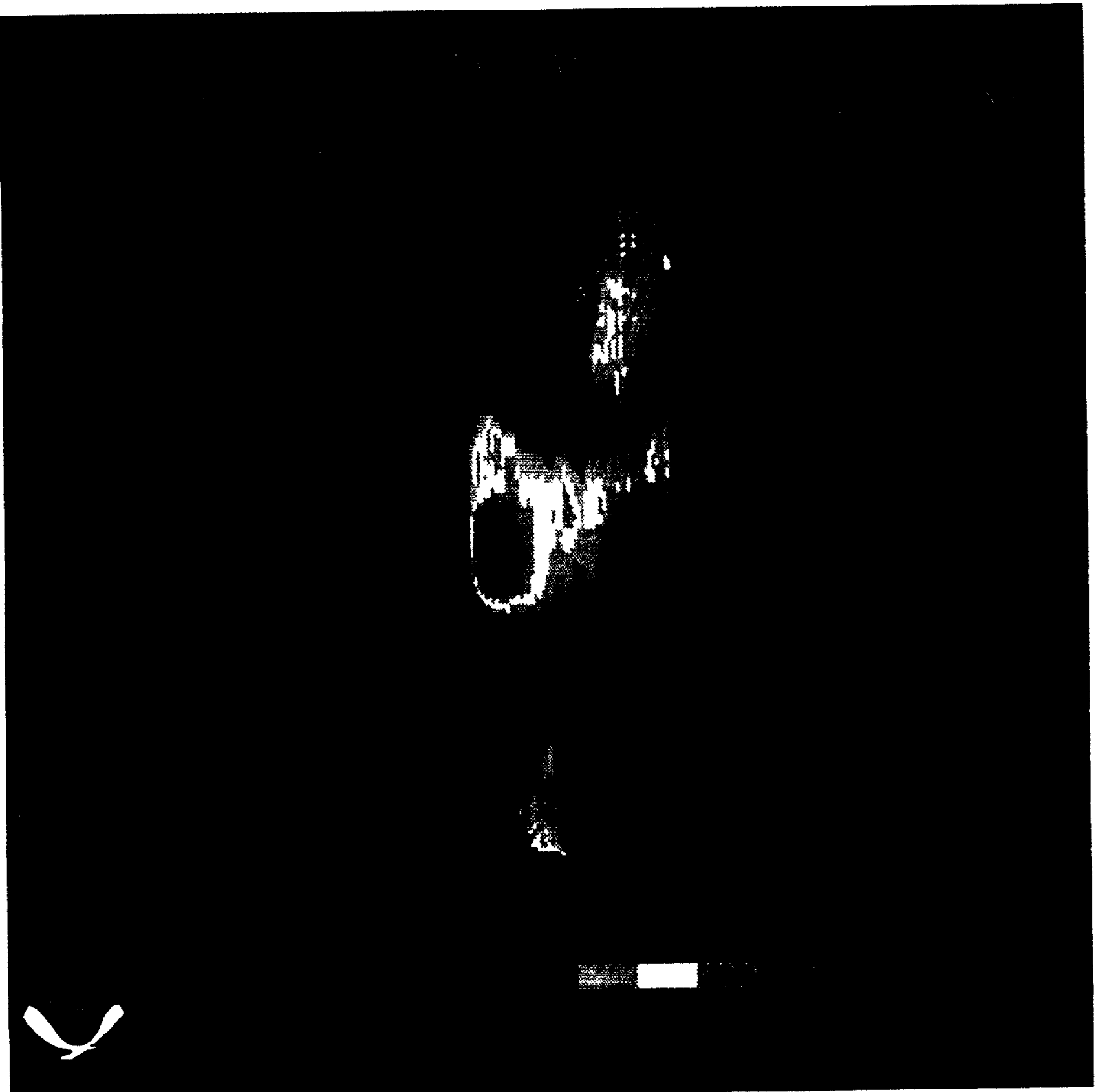

Plate 1. Weekly $1^{\circ}$ zonal time series of $\tau_{\mathrm{SAT} 1}^{\mathrm{A}}$ at $0.5 \mu \mathrm{m}$ over oceans from NOAA 11 AVHRR.

June 29,1989 , to September 8,1994 , of the zonal average $\left(1^{\circ}\right.$ latitude band) $\tau_{\text {SAT1 }}^{A}$. The most striking feature in Plate 1 is the high values in tropical optical thickness coincident with the eruption of Mount Pinatubo. The rapid increase and then gradual decrease in volcanic aerosol content of the tropical stratosphere has been captured, as well as the seasonal transport of this aerosol to high latitudes [Stowe et al, 1992; Long and Stowe, 1994; Grant et al., 1996]. Before the eruption and beginning about a year after the eruption, other seasonal latitudinal variations are evident but to a much smaller degree. These are associated with natural mechanisms which create and disburse aerosols in the troposphere. It is evident from Plate 1 that the northern hemisphere has more aerosol than the southern. This is due to the aerosol sources primarily being restricted to land area (wind-blown dust, fires, and industrial pollutants), of which there are more in the northern hemisphere.

The geographical separation between tropospheric aerosol sources can be seen in Plate 2, which shows the annual mean aerosol optical thickness as depicted by this product from the 2 years before the Mount Pinatubo eruption. It shows that the aerosol over the oceans is far from uniform, being separated into distinct regional areas of maximum optical thickness. The features adjacent to the continents are from wind transported aerosol sources originating on the land: mineral aerosol from the deserts of Africa, Saudi Arabia, and Asia [Prospero and Carlson, 1972]; smoke from biomass burning in central and southern Africa, Central and South America, and Indonesia [Kaufman et al., 1990b; Andreae et al., 1994]; and sulfate aerosols from fossil fuel combustion in the highly industrialized 


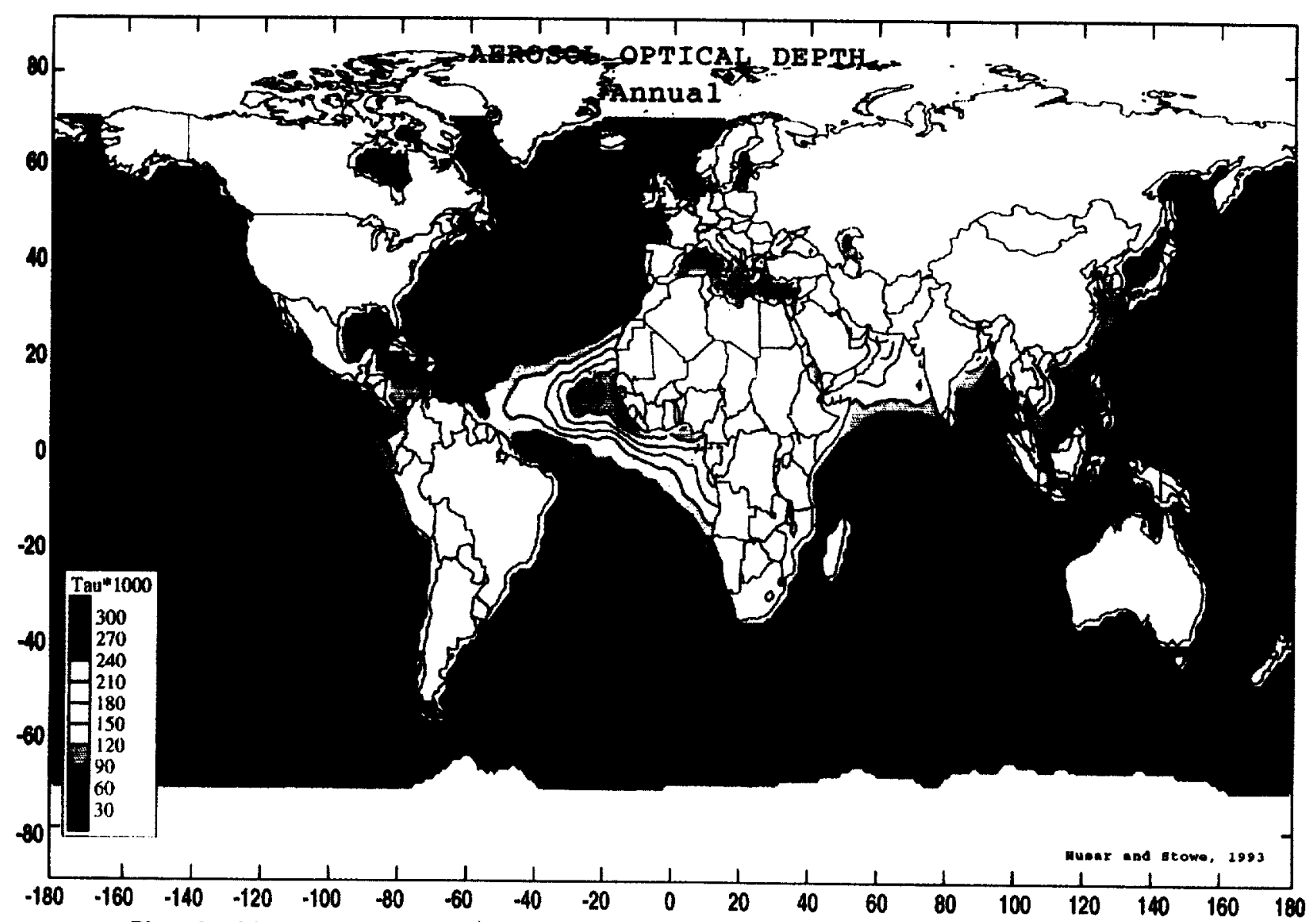

Plate 2. Mean distribution of $\hat{\mathrm{SAT}}_{\mathrm{S} 1}$ at $0.5 \mu \mathrm{m}$ for 2 years prior to the eruption of Mount Pinatubo.

regions of eastern United States, Europe, eastern Asia, and Japan [Husar and Wilson, 1993]. There is also a clear indication of longitudinal bands of aerosol over the southern and northern tropical oceans. These are probably the result of biogenically produced aerosols over the oceans [Charlson et al., 1987]. Of all the aerosol types present over the oceans, the mineral dust is the least similar to the assumed aerosol model and therefore is the most uncertain in terms of optical depth estimates from AVHRR.

\subsection{Validation of the Phase 1 Algorithm}

Sun-photometer data $\tau_{\mathrm{SP}}^{\mathrm{A}}$ collected during two oceanic cruises of the RV Akademik Vernadsky (hereafter AV-89 and AV-91, respectively), and one on the NOAA ship Mount Mitchell (MM-88; this latter corresponds to NOAA 9 data, which were calibrated using prelaunch calibration but without the empirical adjustment developed for NOAA 11, referenced in section 2.2) were used to quantify the accuracy of the $\tau_{S A T}^{A}$ retrievals. The principles and results of selecting and processing the first two matchup data sets are described by Ignatov et al. [1995a, b]. The SP measurements taken within \pm 2 hours of the satellite overpasses were selected. The 10 nearest satellite retrievals, within $300 \mathrm{~km}$ of the ship, were then searched. The 68 reliable matchups (20 obtained for AV-89, 38 for AV-91, and 10 for MM-88) cover large areas in the North Atlantic, in different years: 1988 and 1989 (before Mount Pinatubo) and 1991 (early post Mount Pinatubo), thus being representative of a variety of aerosols over the ocean. Averaging of $\tau_{\mathrm{S} \wedge \mathrm{T}}^{\wedge}$ (over the 10 satellite retrievals closest to the ship) and $\tau_{\mathrm{SP}}^{\mathrm{A}}$ (averaged within $\approx \pm 2$ hours of satellite overpass) was applied to suppress noise resulting from natural variability and measurement errors in both data sources. Comparing the averaged characteristics is also consistent with the gridded NOAA operational product which provides an objective analysis of $\tau_{\mathrm{SAT} \text { i fields }}^{\mathrm{A}}$ over a $\left(1^{\circ}\right)^{2} \times 1$ week space/time box. The accuracy of ${ }^{\Lambda_{\tau}} \tau_{\mathrm{SP}}$ is $\sim 0.02-0.03$ [Ignatov et al., 1995a, b; Reddy et al., 1990].

Figure 2 shows the results of validation of $\tau_{\mathrm{SAT}}^{\mathrm{A}}$ retrievals from NOAA 9 and NOAA 11. The regression is

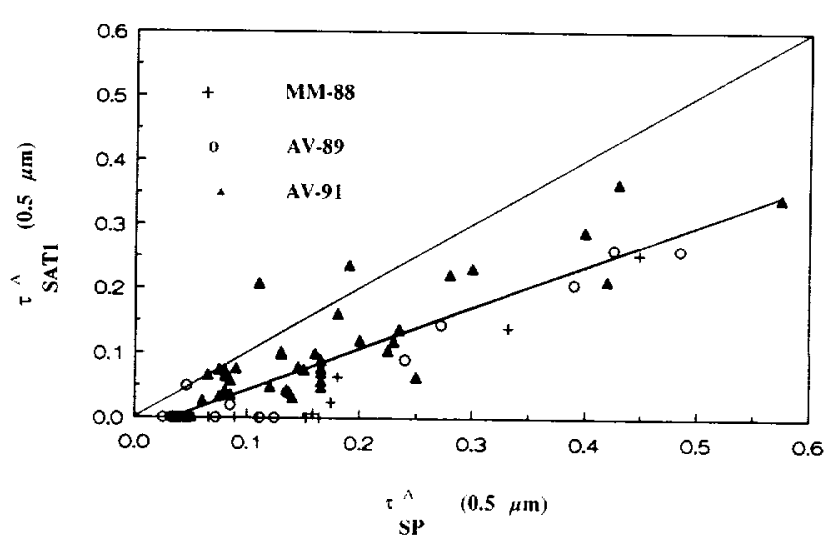

Figure 2. Regression of $\tau_{\mathrm{SAT} 1}^{\mathrm{A}}$ against Sun-photometer aerosol optical thickness at $0.5-\mu \mathrm{m}$ wavelength. 


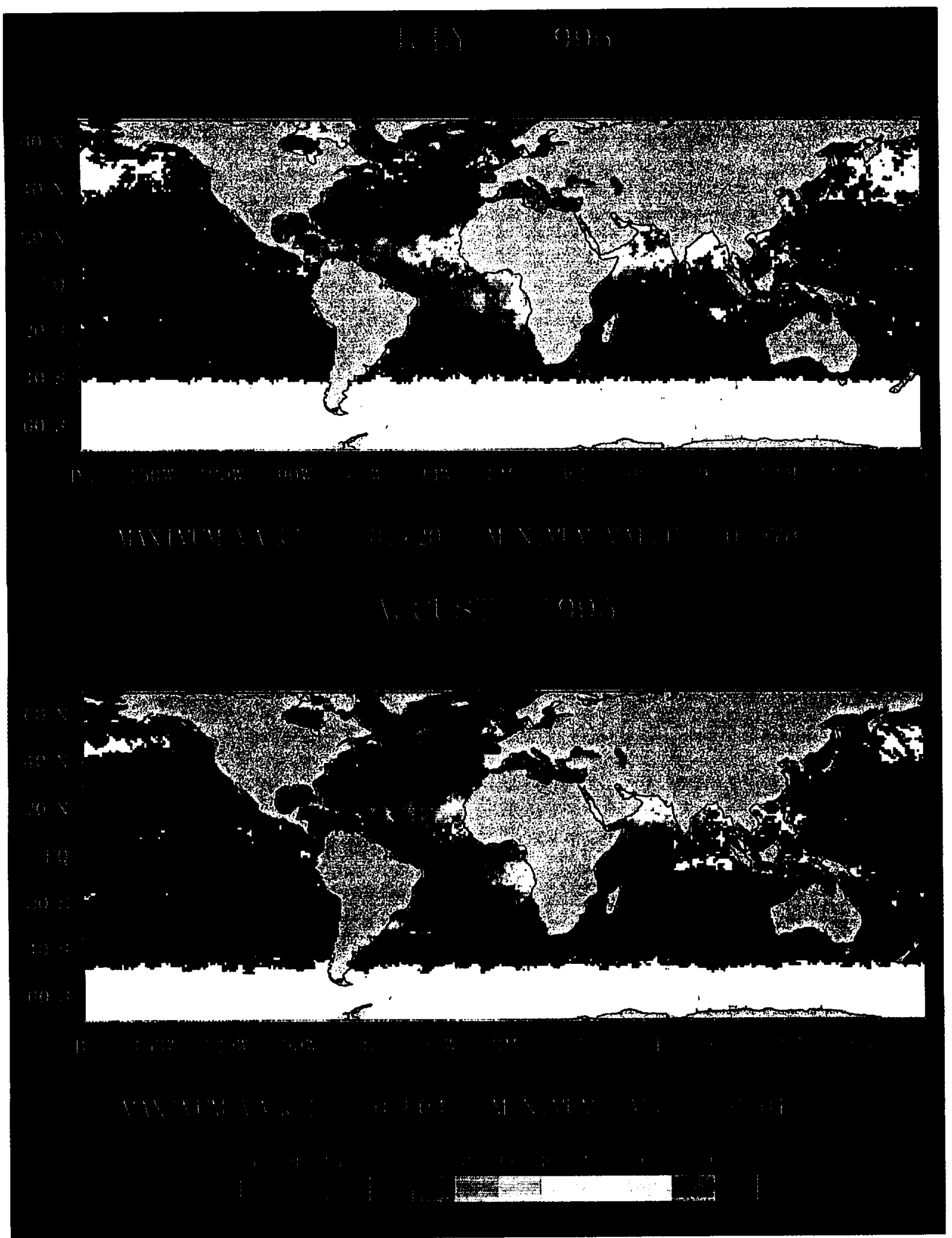

Plate 3. Global distribution of $\tau_{S A \Gamma 2}^{A}$ at $0.63 \mu \mathrm{m}$ from NOAA 14 (top) for July 1995 with pre-launch calibration and (bottom) for August 1995 with postlaunch calibration.

$$
\tau_{\mathrm{SAT} 1}^{\mathrm{A}}=(0.64 \pm 0.05) \tau_{\mathrm{SP}}^{\mathrm{A}}-0.02
$$

with only a slightly nonzero bias. The random error of the regression is about $\sigma_{\tau} \approx 0.045$, with a correlation coefficient of
$R=0.87$. Thus, to a first approximation, the maps shown in section 2.2 should be scaled by the formula $\left(1.56 \tau_{S \wedge \text { II }}+0.03\right)$ to more correctly represent the optical thickness at $0.50 \mu \mathrm{m}$ observed by Sun photometry. 


\section{Revision of the Phase 1 Algorithm: Guidance to Phase 2}

The cause of this bias was the subject of an intense investigation [Ignatov et al., 1995a]. After removal of the scaling of

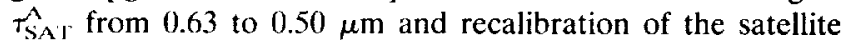
radiances with coefficients determined from postlaunch analysis and adjusted for the dates of the matchup data sets [Rao and Chen, 1995], the inadequacy of the retrieval model is the only reason of discrepancy between $\tau_{\mathrm{SAT}}^{\mathrm{A}}$ and $\tau_{\mathrm{SP}}^{\mathrm{A}}$. The diagnostic analysis was aided by use of the linearized single scattering approximation of the radiative transfer equation [Viollier et al., 1980; Gordon and Morel, 1983], given by the following equation for $\tau^{\mathcal{A}}$ retrieval:

$$
\tau_{\mathrm{SAT}}^{\mathrm{A}}=\frac{\rho-\rho^{R}-\rho^{S} T}{\omega P^{A}} 4 \mu_{s} \mu_{v}
$$

where $\rho$ is an apparent reflectance of the ocean-atmosphere system, defined by normalization of $L$ to the solar flux and overhead illumination geometry; $\rho^{\mathrm{R}}$ is the Rayleigh scattering contribution to the total signal $\rho ; \rho^{\mathrm{S}}$ is the diffuse surface refiectance; $T$ is the total atmospheric transmittance; $P^{A}$ and $\omega$ are the aerosol phase function and albedo of single scattering; $\mu_{v}=\cos \Theta_{\nu} ; \mu_{\mathrm{s}}=\cos \Theta_{\mathrm{s}} ; \Theta_{\nu}$, and $\Theta_{\mathrm{s}}$ are the view and solar zenith angles. Equation (1) shows that the errors in $\tau_{\mathrm{SAT}}^{\mathrm{A}}$ may result from incorrect $\rho^{\mathrm{s}}, \omega$, or $P^{\mathrm{A}}$ since all other terms are reasonably well known. Note that $\rho^{\mathrm{S}}$ participates in (2) as an additive term, and $\left(\omega P^{\mathrm{A}}\right)$ as a multiplicative one. This suggests that the negative bias in the satellite retrievals (removed in operational practice by setting these to zero; note the large number of zero values in Figure 2) comes from having overestimated the oceanic reflectance, and the depressed slope $\left(\mathrm{d} \tau_{\mathrm{SAT}}^{\hat{H}} / \mathrm{d} \tau_{\mathrm{SP}}^{\hat{\mathrm{S}}}<1\right)$ from an incorrect aerosol model $(\omega$ and/or $\left.P^{A}\right)$.

Analysis of the literature by Ignatov et al. [1995a] suggests that $\rho^{\mathrm{s}} \approx 0.2 \%$ rather than $1.5 \%$ for deep clean ocean. Correcting this in the retrieval model and taking into account specular reflection of diffuse downward scattered radiation in a single scattering approximation [Viollier et al., 1980; Gordon and Morel, 1983] removed the negative bias, but a multiplicative underestimation in $\tau_{\mathrm{SAT}}^{\mathrm{A}}$ remained. This result strongly indicated that the $P_{3.5}^{A}(\chi)$ used in the operational retrievals is not representative of the average Atlantic aerosol.

Ignatov et al. [1995a, b] attempted to reconcile $\tau_{\mathrm{SAT}}^{\mathrm{A}}$ and $\tau_{\mathrm{SP}}^{\mathrm{A}}$ by inferring a microphysical model from the wavelength dependence of the $\tau_{\mathrm{SP}}^{\mathrm{A}}$. This gave an Angstrom exponent of about $\alpha=0.6$, which led to setting $\nu \approx 2.5(\nu=\alpha+2)$ in the Junge size distribution. However, using this model removed the systematic discrepancy between $\tau_{\text {SAT }}^{A}$ and $\tau_{\text {SP }}^{A}$ only when it was supplemented by adjusting the imaginary part of the aerosol refractive index to 0.01 . Correlation statistics indicate that this algorithm estimates $\tau_{\mathrm{SAT}}^{\mathrm{A}}$ with little systematic bias or offset: $\tau_{\text {SAT }}^{A} \approx-0.004+(0.98 \pm 0.08) \tau_{\text {Sp. The correlation coefficient }}^{A}$. The for the 68 cases is $R=0.92$, with a random error of $\sigma_{\tau} \approx$ 0.046. Additional analyses of Mie calculations have shown that the imaginary part influences the results of $\tau_{\mathrm{SAT}}^{\mathrm{A}}$ retrieval mainly through decreasing the phase function in the backscatter direction (about $30 \%$ ) rather than through absorption itself (only $10 \%$, consistent with the corresponding albedo of single scattering, $\omega \approx 0.9$ ).

The value of $\omega \approx 0.9$ was thought of as unrealistic, and $A$. Ignatov (submitted manuscript, 1996) tried to estimate an empirical phase function, $P_{\mathrm{emp}, \mathrm{i}}^{\mathrm{A}}\left(\chi_{\mathrm{i}}\right)$, at each matchup point $i$ for

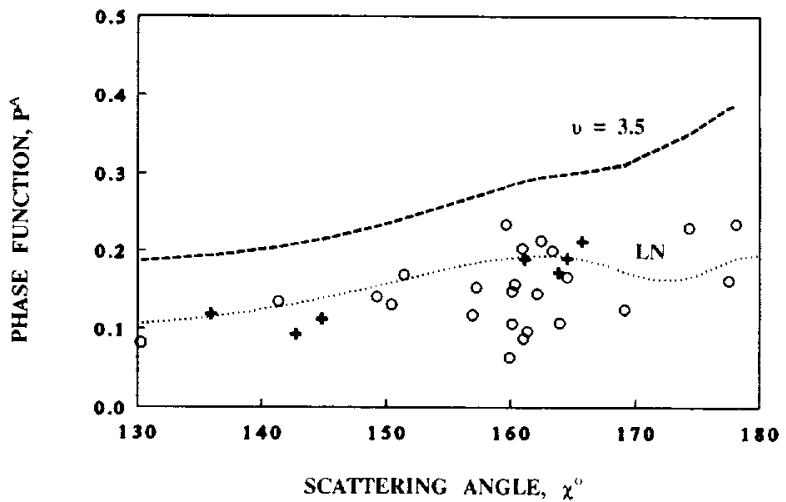

Figure 3. Two model phase functions: $P_{3.5}^{\mathrm{A}}$ (Junge, $\nu=3.5$ ) (dashed) and $P_{\mathrm{LN}}^{\mathrm{A}}$ derived from Mie calculations with lognormal size distribution $\left(r_{\mathrm{m}}=0.1 \mu \mathrm{m} ; \sigma=2.03 \mu \mathrm{m} ; n=1.40\right.$ $0.0 i]$ (dotted), and results of the empirical phase function, $P_{\text {emp }}^{\mathrm{A}}$, estimation for AV-89 (crosses) and AV-91 (open circles). All phase functions are normalized to $4 \pi$.

the particular scattering angle $\chi_{\mathrm{i}}$, having the $\tau_{\mathrm{SP}}^{\mathrm{A}}$ known from the Sun-photometer measurements. The retrieved values of $P_{\text {emp,i }}^{\mathrm{A}}\left(\chi_{\mathrm{i}}\right)$ are plotted versus scattering angle in Figure 3, each point corresponding to one matchup. All the experimental points fall well below $P_{3.5}^{A}$, which explains the systematic underestimation in the operational retrievals (Figure 2 and (2)). One has therefore to find an aerosol phase function which describes the experimental points in Figure 3.

According to D'Almeida et al. [1991], clean maritime aerosol is composed mostly of two components: sea salt (in which the nucleation mode dominates) and sulfate. For a typical relative humidity over the oceans of 70-80\% the lognormal distributions of each are close together with $r_{m} \approx 0.1 \mu \mathrm{m}$, and $\sigma=2.03$ $\mu \mathrm{m}$. Complex indices of refraction for both are also close, about 1.4-0.0i. As a result, the bimodal size distribution of the marine aerosol can be effectively represented by a monomodal lognormal function. Its phase function, shown in Figure 3 , describes the experimental points quite well. Figure 4 shows $\tau_{\mathrm{SAT}}^{\mathrm{A}}$ retrieved with the described lognormal model versus ${ }^{\mathrm{A}} \tau_{\mathrm{SP}}$. The regression gives

$$
\tau_{\mathrm{SAT}}^{\mathrm{A}} \approx 0.01+(0.91 \pm 0.04) \tau_{\mathrm{SP}}^{\mathrm{A}}
$$

with $R=0.93$ and an error of $\sigma_{\tau} \approx 0.04$. This error is inherent to the present single-channel algorithm, and can possibly be reduced with future multispectral algorithms.

Note that the A. Ignatov (submitted manuscript, 1996) study includes only matchups with large aerosol loadings $\left(\tau_{\mathrm{SP}}^{\mathrm{A}} \geq 0.1\right)$, which are not typical for clean maritime conditions [Smirnov et al., 1995]. As a result, the derived empirical phase function may not be representative of clean maritime aerosol, and one needs to be cautious in the geophysical and microphysical interpretation of the derived phase function. Also, application of the derived phase function in the case of small aerosol loadings may be questionable. However, for practical retrievals from AVHRR, error in $P^{\mathrm{A}}$ is of more concern for large aerosol loadings, since absolute systematic error $\delta \tau_{\mathrm{SAT}}^{\mathrm{A}}$ is proportional to $\tau_{\mathrm{SAT}}^{\mathrm{A}}$ for the same relative error in $P^{\mathrm{A}}$ (see equation (2)). Note that reducing the absolute uncertainty $\delta \tau_{\text {SAT }}^{\text {A }}$ is important for climate modeling [e.g., Charlson et al., 1992]. To that end, the lognormal phase function is a reasonable candidate for replacing, the $P_{3.5}^{\mathrm{A}}(\chi)$ used in the phase 1 retrieval algorithm. 


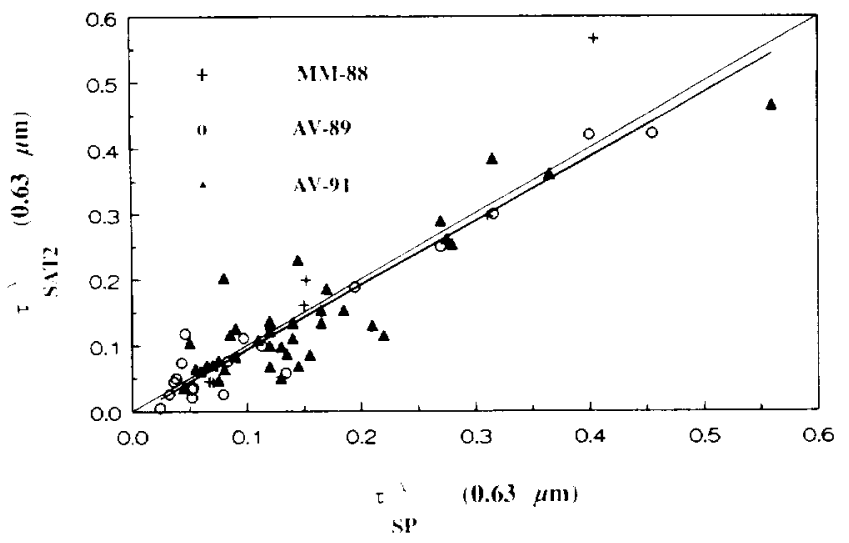

Figure 4. Regression of $\tau_{\mathrm{SAT} 2}$ against same Sun-photometer data set as in Figure 4 but at $0.63 \mu \mathrm{m}$.

The phase 2 model's apparent contradiction to other literature, which recommends using a two- or three-mode lognormal function [World Climate Program, 1983. 1986; Shette and Fenn. 1979; Gathman, 1983; Gras, 1991; Hoppel et al., 1994], requires further investigation but is of little concern for practical use. since the $P_{\mathrm{I} . \mathrm{N}}^{\mathrm{A}}$ is close to the empirically derived one. The premise of that model is its simplicity, in particular fewer numbers of descriptive parameters (each mode requires values of modal radius, standard deviation, and complex index of refraction). This model has been adopted for the operation of NOAA 14, launched in December 1994. Its summary and some preliminary attempts at validation are described in the next section.

\section{Phase 2 Algorithm (March 1995 Onward)}

\subsection{Algorithm Summary}

The second-generation (phase 2) acrosol retrieval algorithm has many features common with phase 1 described in section 2. The difference between the two comes from the fact that the phase 1 algorithm has been carefully validated, and its parameters have been revised based on experimental data, and careful analysis of the recent literature. The Lambertian surface reflectance in the second generation product is lowered 7.5 times, from $1.5 \%$ down to $0.2 \%$. The bidirectional Fresnel reflectance from the flat ocean surface is approximately taken into account by introducing a diffuse glint correction to the phase function, derived from the single scattering approximation [Viollier et al., 1980; Gordon and Morel, 1983]. Its application to the phase 2 algorithm is described in detail by Ignatov et al. [1995a]. We understand restrictions of this procedure, especially at high aerosol loadings and in the vicinity of glint, and are working now on more appropriate quantification of this effect. The aerosol phase function used in the phase 2 algorithm, was derived assuming a lognormal size distribution with $r_{\mathrm{m}}=0.1 \mu \mathrm{m}, \sigma=2.013 \mu \mathrm{m} ; n=1.4-01$.

No scaling is made anymore from the wavelength of measurement $0.6 .3 \mu \mathrm{m}$ to the wavelength of $0.50 \mu \mathrm{m}$, recommended by the World Metcorological Organization as a reference. The reason is that this scaling factor is strongly atmospheric model dependent and may result in a systematic error in the retrieved $\tau_{\text {SAI. }}^{A}$. For those wanting to convert, the scaling factor for the first-generation model is 1.348 and for the second-generation is 1.164 .

\subsection{Testing Phase 2 Algorithm With NOAA 11 Pathfinder} Data (September 1989)

Expected differences in the performance of the two algorithms has been verified globally with data from the AVHRR Atmosphere Pathfinder Program. This is a NASA/NOAA joint program to reprocess NOAA satellite data with community consensus calibration and remote sensing algorithms into a long-term product data set for weather and climate change research [University Corporation for Atmospheric Research (UCAR), 1994]. The AVHRR atmosphere pathfinder data set is being produced at NOAA/NESDIS. Phase Al of this program uses the CLAVR-1 (clouds from AVHRR phase 1) cloud screening algorithm [Stowe et al.. 1991], to produce among some 71 parameters, cloud-free and cloudy radiances in all five channels averaged in $110 \mathrm{~km}$ equal area regions over the globe. Phase A2 uses these area averaged radiances to derive aerosol optical thickness over oceans and radiation budget parameters at the top of the atmosphere. Initially, an 18 -month "benchmark" period from April 1987 to November 1988 (NOAA 9) and September 1989 (NOAA 11 ) is being processed. For this initial run, $\tau_{S A T}$ has been computed with both phase 1 and 2 acrosol algorithms for validation purposes and for continuity with the over 5 years of NOAA 11 data. Figure 5 shows the result of plotting $\tau_{\text {SAT1 }}^{A}$ versus $\tau_{\text {SAT2 }}^{A}$ (converted to $0.50 \mu \mathrm{m}$ for consistency) for September 6, 1989, NOAA 11 data for all $110-\mathrm{km}$ grid cells with cloud-free radiances. The regression line has the form

$$
\tau_{\mathrm{SAT} 1}^{\mathrm{A}}=(0.69 \pm 0.003) \tau_{\mathrm{SAT} 2}^{\mathrm{A}}-0.03
$$

with $R=0.97$ and $\sigma_{\tau}=0 .\left(123\right.$. The relationship between $\tau_{\text {SATI }}$ and $\tau_{S \mathrm{P}}$ (cf. equation (1)) produced a slope and intercept which agrees to those in (3) within the error of estimation. Thus it can be concluded that when globally applied, the phase 2 algorithm yields a result that is similar to what would have been observed had we performed validation with Sun photometers.

\subsection{Application of the Phase 2 Algorithm to NOAA 14 Data}

After the failure of NOAA 11 AVHRR in September 1994, operational production of $\tau_{\widehat{S A T}}$ did not commence until March 1995 using NOAA 14 data. As an example of these initial results, Plate 3 shows a global image of $\tau_{S A 1 Z}^{A}$ for the month of July 1995. It reproduces many of the features present

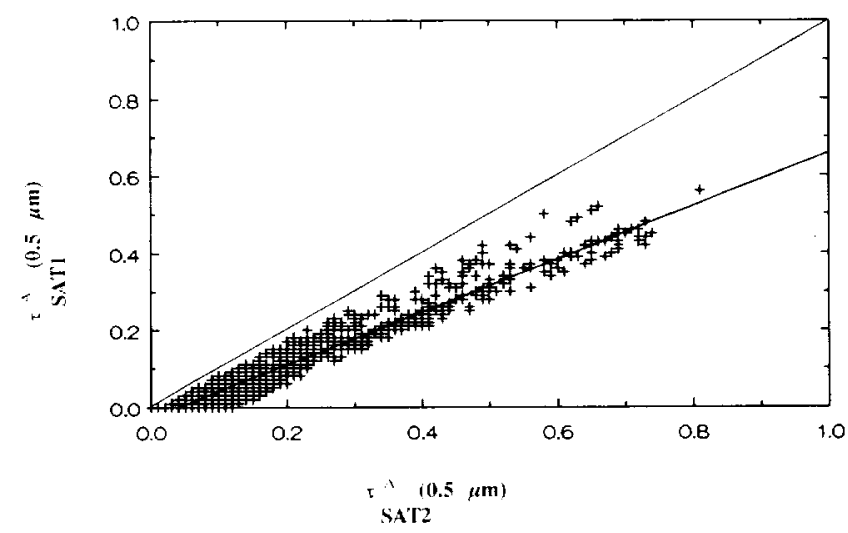

Figure 5. Regression of $\tau_{\text {SATI }}^{A}$ against $\tau_{\text {SAT2 }}^{\wedge}$ at $0.5 \mu \mathrm{m}$ globally, using the AVHRR atmosphere pathfinder processing system for September 6, 1989. 


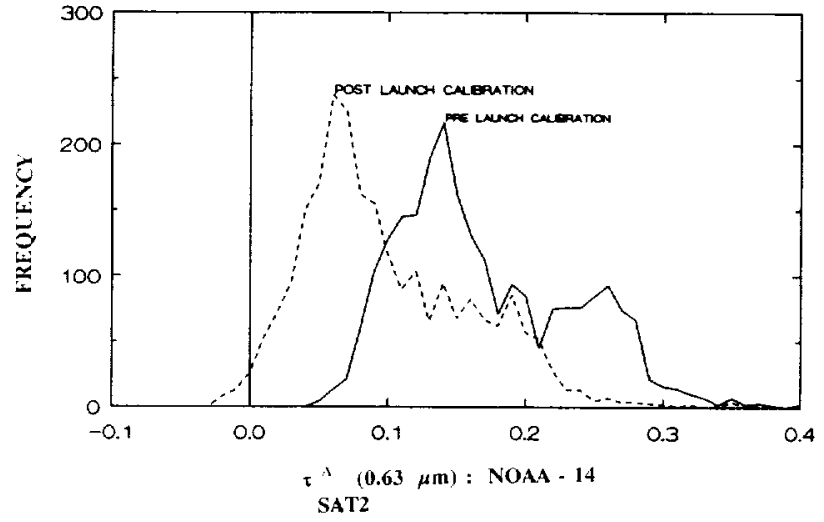

Figure 6. Effect of prelaunch calibration error on $\tau_{\mathrm{SAT} 2}^{\mathrm{A}}$.

in the NOAA 11 maps (cf. Plate 2), but the optical depths appear to be elevated by more than the expected factor of 1.34 (a ratio of underestimation of 1.56 from (1) and conversion factor from 0.63 to $0.5 \mu \mathrm{m}$ of 1.164). Postlaunch investigations into the calibration of NOAA 14 AVHRR channels 1 and 2 (N. Rao, personal communication, 1995), have confirmed revision of prelaunch calibration by $\mathrm{R}$. Mitchell (In-flight characteristics of NOAA AVHRR channels 1 and 2, submitted to IEEE Transactions on Geoscience and Remote Sensing, 1996) and have led to the conclusion that the prelaunch values of calibration coefficients were in error. Rao's revision of these terms was implemented into operations the end of July. The effect on the NOAA 14 aerosol product is shown also in Plate 3, where much more reasonable values of $\tau_{\mathrm{SAT} 2}^{\mathrm{A}}$ appear to be distributed over the globe for August 1995, having about the right degree of enhancement compared with Plate 2. Figure 6 shows quantitatively the effect of applying Rao's postlaunch calibration coefficients to a sample of NOAA 14 data. This shows that $\tau_{\mathrm{SAT2}}^{\mathrm{A}}$ was being overestimated before August 1995 by about 0.08 , on average.

The Sun-photometer method of validation is nearing a reality for NOAA 14. NESDIS has begun collecting $\tau_{\mathrm{SAT} 2}^{\mathrm{A}}$ observations in real time at seven coastal locations where well calibrated and maintained Sun-photometer observations are available, but none of these data sets have been processed as yet [Holben et al., 1996].

\section{Possible Enhancements to the AVHRR Product}

\subsection{Multispectral Retrieval Algorithms}

A third-generation (phase 3 ) algorithm is currently under development. It uses two channels from the current AVHRR. The algorithm will be used to estimate an additional parameter: the Angstrom wavelength exponent $\alpha$ traditionally measured in Sun photometry. This could be used to retrieve an aerosol size parameter, which in turn could possibly be used to adjust the size distribution (scattering phase function) used in the single-channel retrieval algorithm [e.g., Durkee et al., 1991]. This could potentially remove residual errors resulting from departures of the actual aerosol size distribution from the one used in the single-channel retrieval model.

One example of such an algorithm was developed several years ago [Ahmad et al., 1989]. This approach relied upon regression relationships from theoretical radiative transfer model calculations which relate the ratio of aerosol path radiance between two channels to the exponent of the Junge power law model. The retrieved Junge exponent $(\nu=\alpha+2)$ determines the aerosol particle size distribution. It is then used to retrieve the optical thickness from one of the channels, again through the use of theoretical regression relationships, but specifically for that particular Junge exponent (aerosol size distribution).

A graphical illustration of such an algorithm is shown in Figure $7 \mathrm{a}$. On the ordinate normalized radiance (defined in section 2.1) is plotted at the effective wavelength (average wavelength weighted by product of channel response function and solar spectral irradiance) of channel $2(0.83 \mu \mathrm{m})$ of AVHRR, and on the abscissa the same quantity is plotted but for channel 1. Solar and satellite geometries are identical to those used in Figure 1. This has been done for three atmospheric models (tropical, midlatitude, and Arctic) to represent the possible range of water vapor content which affects the radiance in channel 2 due to its filter encompassing several strong bands of water vapor absorption. To each of these three atmospheric models is added the ocean surface reflection model and Junge aerosol size distribution dependent scattering and absorption models used in our initial efforts to improve upon the phase 1 single-channel algorithm [Ignatov et al., 1995a]. Three values of the Junge exponent have been used in this example: $\nu=3.5$ (effective radius, third moment divided by second moment of size distribution, $\left.r_{\mathrm{cff}}=0.21 \mu \mathrm{m}\right), \nu=2.5$ $\left(r_{\text {eff }}=0.79 \mu \mathrm{m}\right)$ and $\nu=1.5\left(r_{\text {eff }}=3.64 \mu \mathrm{m}\right)$. The total number of particles in each model atmosphere was adjusted to yield the same aerosol optical thickness at $0.5 \mu \mathrm{m}$ (heavy dashed line in Figure 7 shown only for midlatitude model). The result is a set of three families of curves, one for each Junge exponent value, relating the change in radiance for the two channels as optical thickness changes. Making up each of these are three curves for each of the three different atmospheric models, showing the effect of variable water vapor on the radiance in channel 2 .

Given an AVHRR observation over a clear ocean at the viewing and illumination angles of Figure 7 (it should fall somewhere in the space bounded by the outermost curves), the corresponding values of $\nu$ and $\tau_{\mathrm{SAT} 3}^{\mathrm{A}}$ can then be read. Automating this procedure is relatively trivial, once a similar set of figures (i.e., look-up tables) have been computed for the range of geometries likely to be observed. The accuracy of the retrieved optical thickness and Junge parameter is dependent not only on the correctness of the assumed model parameters but also on measurement error. As is evident from Figure 10a, measurement noise will introduce larger relative error in the derived parameters as the optical thickness of the aerosol approaches zero (curves converge at $\tau_{\mathrm{SAT} 3}^{\mathrm{A}}=0$, where the ability to separate the effect of different aerosol models vanishes). Quantifying the magnitude of these errors and their sensitivity to independent variables is the subject of current research (e.g., A. Ignatov, Accuracy of aerosol Angstrom exponent derived from two-channel satellite measurement over the oceans, submitted to Applied Optics, 1996).

One source of error, the variable amount of water vapor, can be reduced in two ways: either by providing independent knowledge of the water vapor amount and vertical profile relative to the aerosol profile, not presently available from satellite remote sensing technology, or by using a pair of channels weakly affected by water vapor absorption. Such a pair of channels $(0.63$ and $1.61 \mu \mathrm{m})$ will become available from 


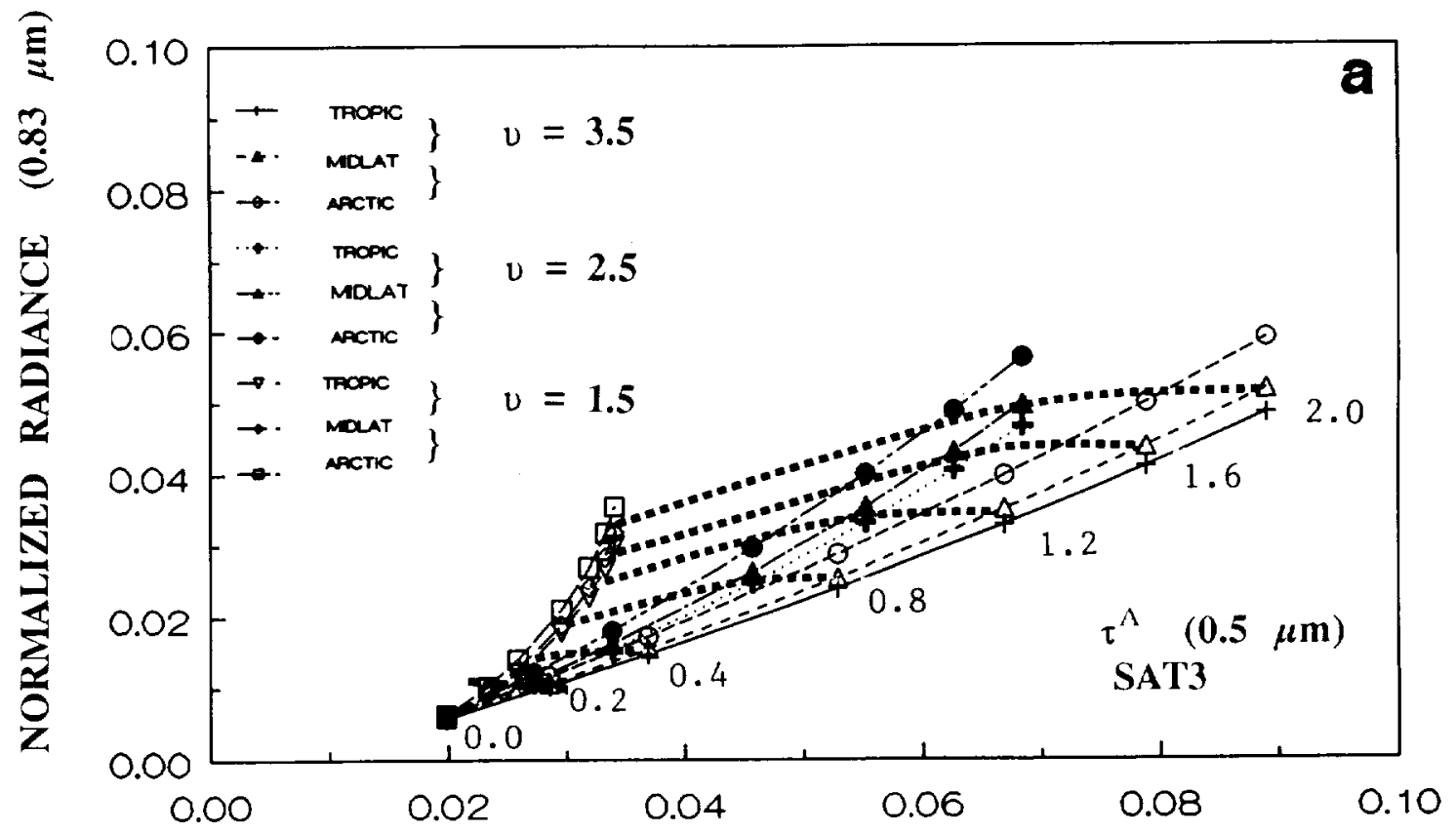

NORMALIZED RADIANCE $(0.63) \mu \mathrm{m})$

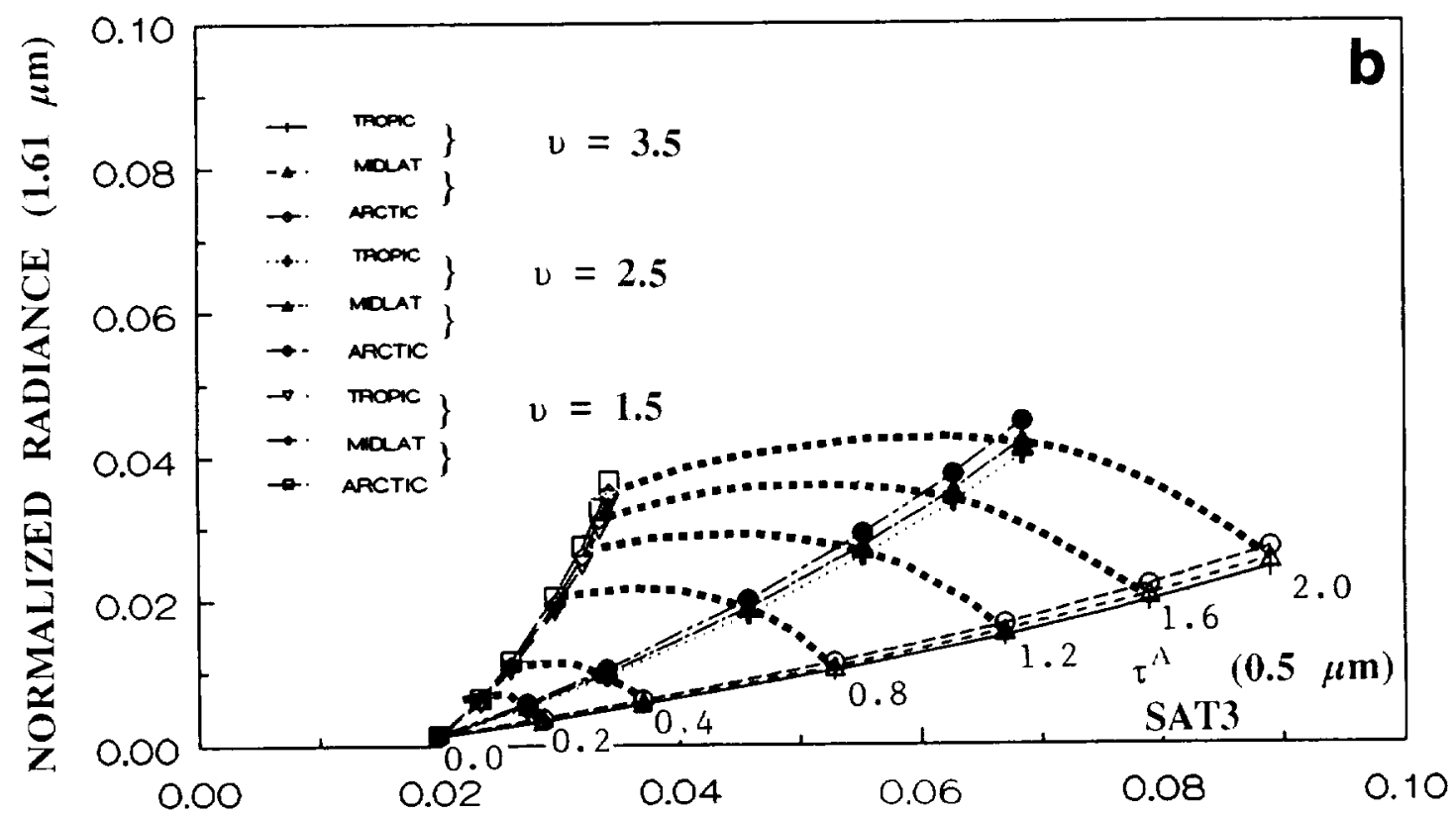

\section{NORMALIZED RADIANCE $(0.63 \mu \mathrm{m})$}

Figure 7. Illustration of the principle of $\tau_{\mathrm{SAT} 3}^{\mathrm{A}}$ and $\nu$ retrieval from two-channel reflectance measurements at (a) 0.63 and $0.83 \mu \mathrm{m}$ and (b) 0.63 and $1.61 \mu \mathrm{m}$ (the heavy dashed lines are contours of $\tau_{\mathrm{SAT} 3}^{\mathrm{A}}$ at $0.5 \mu \mathrm{m}$, shown only for the midlatitude model).

AVHRR with the NOAA-KLM series of satellites, scheduled to commence in 1996. However, because of data storage constraints on-board the spacecraft, only the afternoon satellite, NOAA-L, will provide global coverage at $1.61 \mu \mathrm{m}$ in daytime. To show the potential of retrieving improved aerosol information from these two channels, Figure $7 b$ has been constructed. Not only is the effect of variable water vapor greatly reduced, but the separation of the three families of curves has been increased. This means that for the same relative measurement error, one should be able to obtain more accurate aerosol information at lower values of optical thickness than with the current two AVHRR reflectance channels. A similar pair of channels are available from the Thematic Mapper on the Landsat series of satellites, from the along track scanning ra- 
diometer (ATSR) instrument on the ERS-2 satellite, and from the visible infrared scanner (VIRS) instrument to be launched on the TRMM satellite in 1997.

\subsection{Other Potential Enhancements}

With regard to other aerosol remote sensing issues not yet addressed in our program, it is highly desirable to make retrievals over surfaces with relatively high reflectivity, such as in the regions of oceanic specular reflection or for most land surfaces. A climatology of clear-sky reflectance and its variance could be used as input to radiative transfer model LUTs for the extraction of optical thickness and particle size parameters in these arcas, although the sensitivity of reflected radiation to the presence of aerosols is diminished relative to that over dark ocean surfaces [Kaufman et al., 1990a]. Also, use of infrared retrieval techniques, as other investigators have shown $[\mathrm{Leg}$ rand et al., 1989], can retrieve aerosol optical thickness information over certain geographical areas, such as deserts. Eventually, with the launch of the ocean color temperature scanner (OCTS) and polarization and directionality of Earth reflectances (POLDER) instruments on the Japanese ADEOS satellite and SeaWifs instrument on a commercial satellite in 1996 , and the launch of the EOS polar platform instruments (moderate-resolution imaging spectrometer (MODIS), multiangle imaging spectrometer (MISR), and Earth observing scanning polarimeter (EOSP)) between 1998 and 2003, many other spectral channels as well as linear polarization parameters will become available for the description of the atmospheric acrosol content.

Also, even at the single-channel algorithm level, further improvements could be made by more accurately describing the diffuse glint and introducing the direct glint, both of which will require information about wind speed. Using a microphysical aerosol model that varies by geographical region and provides a phase function that closely matches empirically derived values for each region separately may also improve accuracy. Establishment of ground truth sites with in situ as well as remote sensing data would greatly assist the validation of multispectral techniques.

\section{Discussion}

The phase 2 retrievals show reasonable agreement with Sunphotometer data on the average. Residual scatter indicates that the phase function for real maritime aerosol varies and can be assumed "universal" only within the reported uncertainty limits. For single-channel retrievals the only alternative to a "universal" empirical phase function would involve its parameterization versus $\tau^{\wedge}: P^{\wedge}=f\left(\tau^{\wedge}\right)$, which allows one to keep one unknown under retrieval $\tau^{\wedge}$. The analysis of $\mathrm{A}$. Ignatov (submitted manuscript, 1996) did not confirm this hypothesis, however. Also, oceanic diffuse reflectance is not a universal constant, $\rho^{\mathrm{s}}=0.2 \%$. It may be much higher over turbid coastal waters, and is bidirectional.

We believe that a more complicated two-channel procedure should be introduced only after the potential of the onechannel algorithm is fully realized, its advantages and deficiencies understood, and the necessity and sufficiency of additional measurements convincingly proved. To that end, using the microphysical model which closely reproduces the empirically derived phase function is the logical next step, providing a bridgehead between the present and future generation of aerosol retrieval algorithms. Additionally, the spectral position of
AVHRR channel 1 is not far from the optimal for aerosol retrieval, recommended by Koepke and Quenzel [1981]. So far, the $\mathrm{rms}$ accuracy of the Phase 2 algorithm is $\sigma_{\tau} \approx 0.04$. This estimate is consistent with results of Kaufman [1993], who shows that using a universal relationship between aerosol optical depth and path radiance leads to a maximum error of 0.10 (about $3 \sigma_{\tau}$, assuming a Gaussian distribution of error).

It is recognized that the AVHRR instrument is not the optimum instrument for making aerosol measurements. It has no onboard calibration for its two (a third will be added in 1997) reflectance measuring channels. With the development of spaceborne multispectral imaging spectrometers like MODIS [King et al., 1992], multiangular vicwing radiometers like MISR [Martonchik and Diner, 1992], and ATSR [Mutlow et al., 1994], and polarimetric imaging radiometers like POLDER [Deuze et al., 1993], remote sensing of aerosol physical and chemical propertics should be improved beyond AVHRR's capabilities. Nonetheless, the work that has been done with AVHRR has clearly demonstrated that aerosol remote sensing can be done from space, and that the resulting products over global oceans can provide valuable information on spatial and temporal variability of this important climate forcing parameter [Joussaume and Sadoumy, 1989; Long and Stowe, 1994; Lacis and Mishechenko, 1995]. Efforts are now underway to reprocess the entire AVHRR record from the NOAA afternoon satellites back to 1981 [UCAR, 1994]. Such a climatology, having accounted for calibration drift and the same aerosol retrieval algorithm throughout, will provide a unique data set from which a greater knowledge of the Earth's aerosol characteristics will be gleaned, and against which the value of the future instruments can be measured.

\section{Conclusion}

The second generation single-channel aerosol retrieval algorithm has been described. It has been implemented into the operational processing system for the NOAA 14 satellite, launched on December 30, 1994. The algorithm is based on analysis of three matchup Sun-photometer-NOAA satellite data sets, which revealed errors in the operational NOAA/ NESDIS $\tau_{\mathrm{SAT} 1}^{\mathrm{A}}$ retrievals. A fundamental revision of the oceanic reflectance model was undertaken from analysis of the scientific literature. A new empirical aerosol phase function has been derived from the matchup data. A microphysical aerosol model, which matches the empirical phase function, has been chosen for the retrieval of $\tau_{\hat{S} \mathrm{~A} Y}$. These adjustments to the first generation NOAA/NESDIS aerosol product bring, to a first approximation, the Sun-photometer and satellite data into better than $10 \%$ agreement. It also has been shown that when applied to a global analysis with AVHRR atmosphere pathfinder data sets, the phase 2 algorithm provides $\tau_{S \wedge T}^{\wedge}$ which deviates from $\tau_{S A T 1}^{\wedge}$ in the same way that $\tau_{S P}^{\wedge}$ deviated from $\tau_{\text {SAT1 }}$. Examples of the NOAA 14 aerosol global maps have been presented, which before August 1995, are biased high by AVHRR calibration errors.

Since the $\tau_{\mathrm{SAT}}$ are retrieval model dependent, we call the satellite product a "radiatively equivalent" aerosol optical thickness. The phase 2 algorithm provides unbiased, in the mean statistical sense, aerosol retrievals over oceans. It can be viewed as a procedure for removing the strong angular dependencies from upward radiances (normalizing them to a common geometry), with scaling to acrosol optical thickness measured by Sun photometry. Any remaining noise in the satellite 
retrievals $\left(\sigma_{\tau} \approx 0.04\right.$, see $(3)$ ) follows from variability of the aerosol phase function, aerosol absorption, and oceanic reflectance about their average values, typical for the oceans. Some of this variability may be potentially accounted for by further adding other spectral or angular measurements to the retrieval algorithms; for those, the present NOAANESDIS aerosol product provides a reference level from which improvements can be measured. An example of such an algorithm, with the improvements possible with the $1.61-\mu \mathrm{m}$ channel on the NOAA/KLM series of AVHRR instruments, was presented. Further investigations are needed, together with intensive field measurements, to establish the most globally robust multichannel aerosol retrieval algorithm.

Acknowledgments. Advice from Y. Kaufman, G. Ohring, N. Rao, and R. Mitchell was indispensable in carrying out the present investigation. We thank R. Husar and C. Long for providing figures for this work and $\mathbf{R}$. Ryan and J. Jiles who helped in preparation of them. Of course, none of these data would be available were it not for the dedicated hard work of the Office of Satellite Data Processing and Distribution and particularly of J. Sapper of that office, who implements and maintains the operational production system. This work was done when A.I. was a University Corporation for Atmospheric $\mathrm{Re}$ search visiting scientist at the NOAA/NESDIS Satellite Research Laboratory, on leave from the Marine Hydrophysics Institute, Sevastopol, Crimea, Ukraine. Partial support for A.I. and full support for R.S. has come from NASA contract L-90987C, as part of L. S.'s co-investigator responsibilities on the EOS/CERES Science Team.

\section{References}

Ahmad, Z., J. Sutton, L. Stowe, and N. Rao, A regression method for estimating atmospheric aerosol properties from current and modified versions of the NOAA/AVHRR instrument, in Current Problems in Atmospheric Radiation, 1988, pp. 134-138, A. Deepak, Hampton, Va., 1989.

Andreae, M., B. Anderson, D. Blake, J. Bradshaw, J. Collins, G. Gregory, G. Sachse, and M. Shipham, Influence of plumes from biomass burning on atmospheric chemistry over the equatorial and tropical South Atlantic during CITE 3, J. Geophys. Res., 99, 12,793$12,808,1994$.

Charlson, R., J. Lovelock, M. Andreae, and S. Warren, Oceanic phytoplankton, atmospheric sulfur, cloud albedo, and climate, Nature, $326,655-661,1987$.

Charlson, R., S. Schwartz, J. Hales, R. Cess, J. Coakley Jr., J. Hansen, and D. Hofmann, Climate forcing by anthropogenic aerosols, Science, 255, 423-430, 1992.

D'Almeida, G., P. Koepke, and E. Shettle, Atmospheric Aerosols: Global Climatology and Radiative Characteristics, 561 pp., A. Deepak, Hampton, Va., 1991.

Dave, J., Development of the programs for computing characteristics of ultraviolet radiation: Scalar case, report, contract NAS5-21680, NASA Goddard Space Flight Cent., Greenbelt, Md., 1973.

Deuze, J., F. Breon, P. Deschamps, C. Devaux, M. Herman, A. Podaire, and J. Roujean, Analysis of the POLDER (polarization and directionality of Earth's reflectance), Remote Sens. Environ., 44, $151-168,1993$.

Durkee, P., F. Pfeil, E. Frost, and E. Shima, Global analysis of aerosol particles characteristics, Atmos. Environ., Part A, 25, 2457-2471, 1991.

Gathman, S., Optical properties of the marine aerosol as predicted by the Navy aerosol model, Opt. Eng., 22, 57-62, 1983.

Gordon, H., and A. Morel, Remote Assessment of Ocean Color for Interpretation of Satellite Visible Imagery: A Review, 114 pp., SpringerVerlag, New York, 1983.

Grant, W., E. Browell, C. Long, L. Stowe, R. Grainger, and A. Lambert, Use of volcanic aerosol to study the tropical stratospheric reservoir, J. Geophys. Res., 101, 3973-3988, 1996.

Gras, J., Southern hemisphere tropospheric aerosol microphysics, $J$. Geophys. Res., 96, 5345-5356, 1991.

Griggs, M., Measurements of atmospheric aerosol optical thickness using ERTS-1 data, J. Air Pollut. Control Assoc., 25, 622-626, 1975.
Griggs, M., Satellite measurements of tropospheric aerosols, $A d v$ Space Res., 2(5), 109-118, 1983.

Holben, B. N., et al., Multi-band automatic sun and sky scanning radiometer system for measurements of aerosols, Remote Sens. Environ., in press, 1996.

Hoppel, W., G. Frick, J. Fitzgerald, and R. Larson, Marine boundary layer measurements of new particle formation and the effects nonprecipitating clouds have on aerosol size distribution, $J$. Geophys. Res., 99, 14,443-14,459, 1994.

Husar, R., and W. Wilson, Haze and sulfur emission trends in the eastern United States, Environ. Sci. Technol., 27, 2-16, 1993.

Ignatov, A., L. Stowe, S. Sakerin, G. Korotaev, Validation of the NOAANNESDIS satellite aerosol product over the North Atlantic in 1989, J. Geophys. Res., 100, 5123-5132, 1995a.

Ignatov, A., L. Stowe, R. Singh, D. Kabanov, and I. Dergileva, Validation of NOAA/AVHRR aerosol retrievals using sun-photometer measurements from RV Akademik Vernadsky in 1991, Adv. Space Res., 16(10), 95-98, 1995b.

Joussaume, S., and R. Sadourny, Desert dust and climate: Investigations using atmospheric general circulation model, in Paleoclimatology and Paleometeorology: Modern and Past Pattems of Global Atmospheric Transport, edited by M. Leinen and M. Sarnthein, Kluwer, Boston, Mass., 1989.

Kaufman, Y., Aerosol optical thickness and atmospheric path radiance, J. Geophys. Res., 98, 2677-2692, 1993.

Kaufman, Y., R. Fraser, and R. Ferrare, Satellite measurements of large-scale air pollution: Methods, J. Geophys. Res., 95, 9895-9909, 1990a.

Kaufman, Y., J. Tucker, and I. Fung, Remote sensing of biomass burning in the tropics, J. Geophys. Res., 95, 9927-9939, $1990 \mathrm{~b}$.

King, M., Y. Kaufman, P. Menzel, D. Tanre, Remote sensing of cloud, aerosol, and water vapor properties from the moderate resolution imaging spectrometer (MODIS), IEEE Trans. Geosci. Remote Sens., 30, 2-27, 1992.

Koepke, P., and H. Quenzel, Turbidity of the atmosphere determined from satellite: Calculation of optimum viewing geometry, J. Geophys. Res., 84, 7847-7856, 1979.

Koepke, P., and H. Quenzel, Turbidity of the atmosphere determined from satellite: Calculation of optimum wavelength, $J$. Geophys. Res., 86, 9801-9805, 1981.

Kovotyev, G., S. Sakerin, A. Ignatov, L. Stowe, and P. McClain, Sunphotometer observations of aerosol optical thickness over the North Atlantic from Soviet research vessel for validation of satellite measurements, J. Atmos. Oceanic Technol., 10, 725-735, 1993.

Lacis, A., and M. Mishechenko, Climate forcing, climate sensitivity, and climate response: A radiative modeling perspective on atmospheric aerosols, in Aerosol Forcing of Climate, edited by R. J. Charlson and J. Heintzenberg, pp. 11-42, John Wiley, New York, 1995.

Legrand, M., J. Bertrand, M. Desbois, L. Meneger, and Y. Fouquart, The potential of infrared satellite data for the retrieval of Saharan dust optical depth over Africa, J. Appl. Meteorol., 28, 309-318, 1989.

Long, C, and L. Stowe, Using the NOAA/AVHRR to study stratospheric aerosol optical thickness following the Mt. Pinatubo eruption, Geophys. Res. Lett., 21, 2215-2218, 1994.

Martonchik, J., and D. Diner, Retrieval of aerosol and land surface optical properties from multi-angle satellite imagery, IEEE Trans. Geosci. Remote Sens., 30, 223-230, 1992.

McClain, P., Global sea surface temperatures and cloud clearing for aerosol optical depth estimates, Int. J. Remote Sens., 10, 763-769, 1989.

McClain, P., W. Pichel, and C. Walton, Comparative performance of AVHRR-based multichannel sea surface temperatures, J. Geophys. Res., 90, 11,587-11,601, 1985.

Mutlow, C., A. Zavody, I. Barton, and D. Llewellyn-Jones, Sea surface temperature measurements by the along track scanning radiometer on the ERS1 satellite: Early results, J. Geophys. Res., 99, 22,57522,588, 1994.

Prospero, J., and T. Carlson, Vertical and areal distribution of Saharan dust over the western equatorial North Atlantic Ocean, $J$. Geophys. Res., 77, 5255-5265, 1972.

Rao, N., and J. Chen, Inter-satellite calibration linkages for the visible and near-infrared channels of the advanced very high resolution radiometer on the NOAA-7, 9, and -11 spacecraft, Int. J. Remote Sens., 16, 1931-1942, 1995.

Rao, N., L. Stowe, and P. McClain, Remote sensing of aerosols over 
oceans using AVHRR data: Theory, practice and applications, Int. $J$ Remote Sens., 10, 743-749, 1989.

Reddy, P., F. Kreiner, J. DeLuisi, and Y. Kim, Aerosol optical depths over the Atlantic derived from shipboard sunphotometer observations during the 1988 Global Change expedition, Global Biogeochem. Cycles, 4, 225-240, 1990.

Shettle, E., and R. Fenn, Models for the aerosols of the lower atmosphere and the effects of humidity variations on their optical properties. AFGL Tech. Rep., TR-79-0214, 94 pp., 1979.

Smirnov, A., O. Ershov, and Y. Villevalde, Measurement of aerosol optical depth in the Atlantic Ocean and Mediterranean Sea, Proc. SPIE Int. Soc. Opt. Eng., 2582, 203-214, 1995.

Stowe, L., Cloud and aerosol products at NOAA/NESDIS, Paleogeogr. Paleoclimatol. Paleoecol., 90, 25-32, 1991.

Stowe, L., P. McClain, R. Carey, P. Pellegrino, G. Gutman, P. Davis, C. Long, and S. Hart, Global distribution of cloud cover derived from NOAA/AVHRR operational satellite data, Adv. Space Res., $11(3), 51-54,1991$.

Stowe, L., R. Carey, and P. Pellegrino, Measuring the Mt. Pinatubo aerosol layer with NOAA-11 AVHRR data, Geophys. Res. Lett., 19 , $159-162,1992$.

UCAR, The NOAA-NASA Pathfinder Program, 22 pp., The Univ. Corp. for Atmos. Res., Boulder, Colo., 1994.
Viollier, M., D. Tanre, and P. Deschamps, An algorithm for remote sensing of water color from space, Boundary Layer Meteorol., 18 , 247-267, 1980.

World Climate Program, Report of the experts meeting on aerosols and their climatic effect, Rep. WCP-55, 107 pp., World Meteorol. Organ., Geneva, 1983.

World Climate Program, A preliminary cloudless standard atmosphere for radiation computation, Rep. WCP-112, 53 pp., World Meteorol. Org., Geneva, 1986.

A. M. Ignatov, Marine Hydrophysics Institute, Sevastopol 33505, Crimea, Ukraine.

R. R. Singh, SM System and Research Corporation, Inc., 4201 Northview Drive, Suite 301, Bowie, MD 20716.

L. L. Stowe, Office of Research and Applications, NOAA/NESDIS, E/RA11, NSC-Room 711E, Washington, DC 20233. (e-mail: Istowe(a) nesdis.noaa.gov)

(Received February 7, 1996; revised June 21, 1996; accepted June 21, 1996.) 